\title{
An Overview on the Pre-School Teachers' Psychological Readiness while Working with Gifted and Talented Children
}

\author{
Yulia Zhurat, Bohdana Holyk, Oksana Polishchuk
}

The problem of giftedness is now becoming more urgent, and therefore every educator working in pre-school institutions should be improved, look for more and more new ways to work with gifted children, try to create comfortable conditions for such children, to improve and develop themselves, only in that case they will be well psychologically prepared to work with gifted children. It should be solved the problem of psychological training of nursery teachers precisely for work with gifted children. After all, the educator creates an atmosphere that can inspire children or destroy their selfconfidence, or encourage or repress interests.

Keywords: gifted and talented children, preschool institution, psychological readiness, giftedness, self-confidence, individual approach.

\section{Introduction}

The problems of education and upbringing the gifted and talented children are becoming very important, especially in the context of a preschool institution as one of the first institutions for child socialization. In the context of modern trends in humanity development, there is an urgent need to create a system of search, selection and pedagogical support for the nation's future intellectual elite from pre-school age.

At the same time, according to the analysis of the preschool education institutions activity, it is quite common for the development and upbringing the gifted children in practice to use traditional approaches that do not fully take into account the psychological peculiarities of the gifted and the work features with them. Even if innovative educational programs are implemented in pre-school settings, teachers are often not ready enough to work with the gifted children. As a consequence, the children's natural potential without the necessary support may remain undetected at certain times. 
Therefore, the development of preschool educators' psychological readiness to work with gifted children, capable of contributing to the identification and the talent support of each preschooler, the realization of his/her unique natural potential, is relevant.

\section{Analysis of the recent researches and publications}

Theories of genius were explored by V. Ananyev (2003), V. Chudnovskyi (1990), G. Kostyuk (2001), S. Rubinstein (2000), B. Teplov (1985) and others. Among contemporary Ukrainian scholars, L. Lipova (2003), V. Molyako (2005), G. Tarasova (2005), L. Vasylchenko (2017), addressed various aspects to the «gifted child» concept. The concept of «psychological readiness for activity» was introduced into psychological circulation in 1976 by Belarusian researchers M. Dyachenko and L. Kandybovych (1976). Readiness for activity as a certain state of mental functions is considered by K. Platonov (1972), L. Dolynskaya (2016), K. Durai-Novakov (1983), M. Dyachenko, L. Kandybovych (1976), G. Kostyuk (2001) etc.

The main purpose of this article is to disclose the content of the preschool teachers psychological readiness to work with gifted children, to determine the structure of the preschool teachers psychological readiness, to study the level and ways of improving the their psychological readiness to work with talented children.

\section{The main material}

Despite the fact that the study of the genius phenomenon has attracted the attention of researchers since ancient times and is relevant nowadays, there is no unambiguous interpretation of this concept in psychological and pedagogical science. This is explained by the enormous complexity of the very gifted child phenomenon and the multifaceted aspects of its study. Some authors, both national and foreign, mention dozens of different definitions to this concept. However, in the paradigmatic sense the concept «gifted child» is accepted by scientists, and its various aspects are actively researched by scientists, methodologists, practitioners.

The scientific literature analysis on the problem under study indicates that, according to R. Stenberg, gifted is a multidimensional formation that cannot be reduced to a coefficient of intelligence, creativity or motivation, it is unique, so the preschool teacher needs to take into account the diversity of its forms discovery.

R. Sternberg (2000) believes that talent is a combination of intellectual ability, creativity and perseverance. 
The scientific research analysis on the gifted children problem suggests that the important characteristics of the talented children, which apparently shows their giftedness, is the manifestation of high cognitive activity, the speed of mental operations, the formation of logical thinking, the wealth of active vocabulary, establishment of the creative fulfillment revealing of an individual approach in the tasks implementation, developed imagination and fantasy, originality in behavior, increased sense of problem situation, communication peculiarity that can be expressed in intonation, facial expressions, gestures and etc.

The early talent display will help to make the mistake of determining each child's future, especially at the age when it is gift that has the optimal natural conditions for its formation.

There are well-known signs of giftedness, which are shown quite often in the practice of education:

1. Gifted and talented children, as a rule, are extraordinary personalities. They cannot «fit in» with the standard framework, which annoys all the children of the group.

2. Talented, capable children do not accept anything by faith. They demand evidence, and when they are scarce or there aren't any, they propose their own solution.

3. They are experiencing a «search state» almost permanently. Constant reading of different books, conducting experiments (sometimes without following the necessary rules), constant questions that require reasoned answers all require the preschool teacher the moral support and willingness to understand the student.

4. Gifted children tend to be extremely emotional and so vulnerable that they respond very easily to any comment.

That is why the teacher should possess some knowledge about the types of giftedness, since children with different its types need a different approach, different systems of work.

Without being aware on the giftedness types, some of them may simply not be noticed, accepting the peculiarity of the child's mental and creative activity for its indiscipline or even oddity, so knowledge of the types of gifted children is necessary in order to properly assess the child's capabilities and help him/her to solve problems, to properly orient them in choosing the future profession.

Gift is always broken based on the child's favorite activity. If you see a bright, steady interest in a child's activity, it is always a sign that he/she may have some type of giftedness.

By types of giftedness it is meant the area of knowledge or the sphere of life in which the ability is affected. It is known that a child cannot 
be talented in everything. If one area of activity is very close to it, then others can be extremely distant. It is important for each of us to find our own way in life and devote the maximum of our time to it. That's just how personality develops.

Domestic and foreign scientists are interested in the problem of determining the giftedness types. Scientists take a different approach to solving this problem, that is, the term «gifted child» is applied to different abilities of children. Giftedness is a multifaceted phenomenon with various interpretations, and it manifests itself in different stages. Therefore, there are many types of giftedness. In our view, D. Bogoyavlenskaya (2003), O. Molyako (2005), V. Shchors (2007) suggested the criteria for classification of the giftedness types. classified as:

In particular, according to D. Bogoyavlenskaya (2003) the gift is

I. Explicit and hidden. The form of giftedness manifests itself as explicit, observed in the activity of the child vividly and clearly and hidden, it is manifested in a hidden, veiled form.

II. Potential and relevant. The giftedness formation degree can be potential because it presents certain opportunities, potential for high achievements, but not realized at the moment of activity and due to their functional insufficiency, actual it is revealed, the obvious giftedness, i.e. noticed by psychologists, parents. Children who demonstrate this kind of giftedness are called talented.

III. Early and late. Features of age development indicate that giftedness can be manifested both in childhood and adulthood, so there is an early - late giftedness.

IV. General and special. The criterion of manifestations latitude in different types of activity presupposes division according to the individual and psychological characteristics of a person, expressing his / her readiness to master activities, successful mastering and fulfillment - according to his / her abilities.

Psychological features of gifted children, along with the specifics of social order for gifted children, determine certain accents in understanding the basic goals of pre-school education and upbringing, which are defined as the formation of knowledge, abilities and skills in certain subject areas, and creating the conditions for cognitive and personal development. Gifted children must acquire knowledge from all subject areas that are part of preschool education. For everybody (preschool, parents, teachers), the most important purpose of education is to provide the conditions for the discovery and development of all abilities and talents with a view to their further realization in professional activity. It should be emphasized that it is 
these very children that society, in the first place, hopes to solve the urgent problems of modern civilization. Thus, to support and develop the child's individuality, not to lose, to slow down the growth of his or her abilities is a particularly important task of educating gifted children.

The main goals of the education of gifted children are determined taking into account the qualitative specificity of giftedness certain type, as well as the psychological patterns of its development. Thus, the following can be distinguished as the general goals of a preschool education institution for the education of gifted children:

1) developing the spiritual and moral foundations of the gifted child's personality, higher spiritual values;

2) forming conditions for the development of creative talent;

3) progressing the individuality in the gifted child (identification and disclosure of identity and individual identity and its capabilities);

4) providing broad, high-level pre-school preparation that leads to the development of a holistic outlook and a high level of competence in different areas of knowledge in accordance with the children's individual needs and inclinations (Korol, 2010, p. 13).

The basic principles of teaching gifted children in pre-school institutions include (Komisarova, Vedmedenko \& Bilogorna, 2014, p. 34):

- developmental learning principle. This principle means that the goals, content, teaching methods should contribute not only to the acquisition of knowledge and skills, but also to cognitive development, as well as to the education of the students' personal qualities;

- learning individualization and differentiation principle. It is that the aims, content and process of learning should take as fully as possible into account the children's individual and psychological characteristics, in whom individual differences are expressed in a vivid and unique way;

- accounting for age opportunities principle. This principle implies that the content of education and teaching methods are in line with the specific characteristics of gifted children at various age stages, as their higher opportunities can easily provoke an overestimation of the learning difficulties levels, which can lead to negative consequences.

Gifted children, as a special category, require pre-school teachers to constantly encourage creative initiatives, find new methods and forms of productive work, increased attention and specific approaches. Therefore, the problem of the teachers' psychological readiness to work with gifted children covers not only the issue of the professional competence of the teacher, but also the need for systematic development of skills and professionalism. 
The concept of «psychological readiness for activity» was introduced into psychological circulation in 1976 by Belarusian researchers M. Dyachenko and L. Kandybovych (1976). So there are two approaches to interpreting the essence of psychological readiness: functional and personal. Readiness for activity as a certain state of mental functions is considered by the representatives of the first approach (K. Platonov (1972) etc.). Being sufficiently formed, this state provides significant achievements in the activity. Psychological readiness as a result of preparation for a specific activity is considered by representatives of the second approach (L. Dolynska (2016), K. Duray-Novakova (1983), M. Dyachenko, L. Kandybovych (1976), G. Kostyuk (2001) etc.). In this case, readiness is interpreted as an integral formation of personality, which combines motivational, cognitive, emotional-volitional components, knowledge, abilities, skills, personal qualities, adequate to the requirements of the activity (Demchenko, 2008, p.16).

An assessment of the real levels of the psychological readiness formation of pre-school teachers to work with gifted children should be made on the basis of certain structural components of readiness, criteria (motivational-volitional, intellectual-operational, evaluation-reflexive) and content characteristics of these components (readiness indicators). Therefore, we described the psychological readiness of the nursery teacher to work with gifted children in the following scheme: (Afanasyeva, 2005, p. 29).

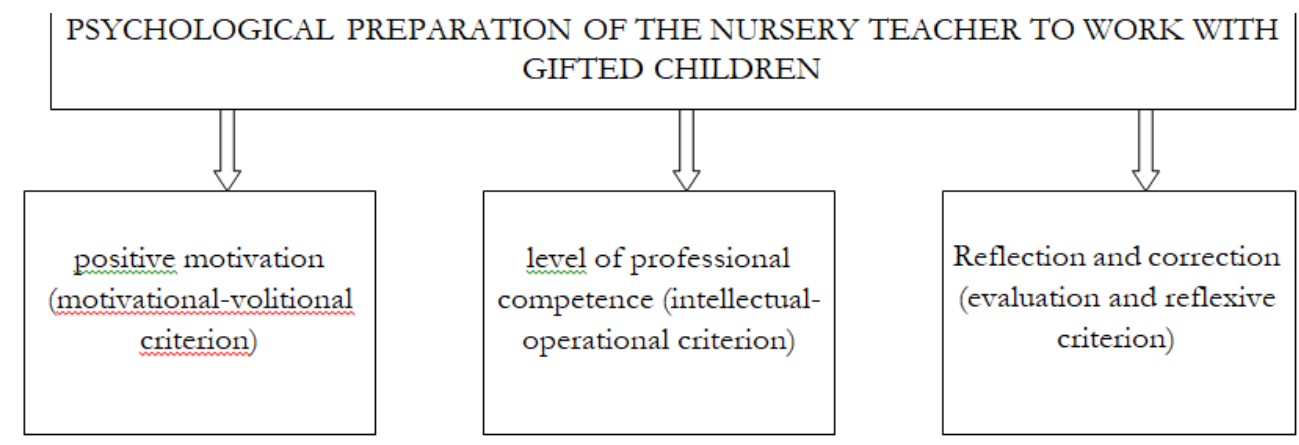

Fig. 1. The structure of the psychological readiness of the nursery teacher to work with gifted children

The motivational and volitional criterion is the awareness of one's professional goals, values, principles, the presence of interest in educational work in the institution, love for children, humanism, democracy and so on. The intellectual-operational criterion reflects the presence of the necessary, 
general, humanitarian and special knowledge of the theory and methodology of educational work, professional skills. Assessment-reflexive criterion of readiness characterizes the educator from the point of view of his ability to analyze the results of his activity, his awareness of his level of professional preparation for the realization of the purpose and tasks of work, as well as an awareness of the need for professional self-education, self-improvement.

To analyze the level of psychological readiness of teachers to work with gifted children in practice, a set of methods is used (questionings, interviews, survey, the method of determining the desire to work with gifted children P. Torrans (1963), self-monitoring method of Snyder), which in the complex gives a certain idea of the nature of problems and difficulties that the nursery teacher has got while working with gifted children.

During the academic year 2018-2019, «Montessori School aged from 3 to $7 »$, pre-school educational establishment «Kalynonka» in Zalishchyky town, was selected as the base of the study. The total number of respondents was 45 pre-school teachers, including 2 tutors-methodologists.

In the institution of pre-school education «Montessori School aged from 3 to 7 », unlike the «Kalinonka», classes with didactic aids and materials by M. Montessori (2004) are added to the educational program of the preschool children development, which allows to better identify and reveal the abilities of children.

At the beginning of the study, we conducted a front-line survey of preschool educators, which, in order to form a representative sample, was divided into groups depending on:

1) age: $8.6 \%$ of respondents from $24-34$ years old, $30.4 \%$ were from 35 to $44 ; 38,6 \%$ were from 45 to $54 ; 22,4 \%$ were from 55 to 70 years old;

2) work experience: $3 \%$ of respondents from 1 to 13 years old; $23.4 \%$ were from 14 to $22 ; 58.6 \%$ were from 23 to $31 ; 15 \%$ were 32 to 46 ;

3) type of preschool institution: traditional type of the pre-school institution is $50 \%$, specialized type is $50 \%$.

There were used such psychological methods as: observation, testing, questioning, and interviewing methods.

In the process of diagnosis we paid attention to external circumstances, namely the emotional response of the respondents to the problem of working with gifted children and the need to increase the developmental interaction effectiveness. Diagnosis was performed in a productive dialogue and round table setting.

Observations of nursery teacher work, conversations with pre-school methodologists focused our attention on the study of the respondents' age characteristics, professional burnout, emotional exhaustion, the need for corrective psychological work to prevent outlined display of the success of 
the gifting development. For clearer results, we kept observations track records that we relied on during the analysis of the study.

Diagnosing the readiness of teaching staff to work with gifted children, we pursued the goal:

- determine the overall level of teachers' readiness to work with gifted children;

- state the general list of components by which pedagogical employees successfully carry out their activities;

- specify some difficulties or gaps in preparation.

To identify the level of teachers' readiness to work with the gifted the questionnaire was formulated in this way «Are you confident in working with gifted children» 5\% have chosen «a», (yes) - this indicates that there are a minority of educators, confident in their abilities and ready to work for new ideas with gifted children, for the sake of optimal results and a sense of joy from the work.

$25 \%$ chose «b» (no) - this indicates that $25 \%$ of educators are ready to train only ordinary children and do not even think about working with gifted children.

$57 \%$ - picked «V 》 (unsure, most likely, no) - this indicates that the largest number of pre-school teacher varies capabilities and most likely not ready for the learning process with gifted children, because the knowledge that the teacher needs improve and constantly update in the special courses that will be to train highly qualified talent specialists.

Questions to identify a cognitive component: «Is it possible that some of your ideas can make a big difference to work and found gifted children? ». The majority of respondents (45\%) chose the answer - b) yes, under favorable conditions. This indicates that most caregivers have some knowledge of the work and identification of gifted children, but not enough. It is necessary to increase your level of readiness to work with a gifted child and to systematize their knowledge.

The third question concerned the practical component: «Do you think that modern methods and forms of work with gifted children can be improved?» The more often responds were as follows: a) yes - got $36 \%$ and b) no, they are quite good $-38 \%$. This indicates that educators are almost equally divided into those who are comfortable with modern forms of work with gifted children and who are not going to change anything in their work, and those who are willing to work on finding new forms and methods for working with gifted children.

An important component of the teachers' psychological readiness to work is the ability to blend in a new team, the ability to communicate, discuss with colleagues. This aspect of the activity was related to a question 
to which we received the following answers: $61 \%$ of pre-school teachers have chosen option «a» - it indicates a high level of teachers' communicative development, the ability to hear others and listen to the others opinions; $28 \%$ chose the «b» option, which shows no ability to listen to others.

Analyzing the results of the teachers' survey on their readiness the following conclusions can be drawn from working with gifted children and they are: a certain number of nursery teachers showed a sufficiently persistent, self-confidence in their knowledge. Since, there is a lack of communicative interaction and their interpersonal cooperation will not always allow them to help others, and to listen to the mentioned disadvantages and mistakes in working with children, shows a certain seclusion of the teacher, which hinders his/her self-development; $11 \%$ of educators show no interest in discussions with their colleges, they see it as an unnecessary dispute that only contributes irritation and in no way affects the improvement of educational process.

Generalization of the studied results showed that each teaching staff has got some achievements and their problems, difficulties, disadvantages. Through this investigation, we became convinced that the problems related to the readiness of the pedagogical staff to work with gifted children are mainly components related to the nursery teacher's psychological readiness to work with the gifted; formation and implementation of programs for individual development and self-development of gifted children; the ability of the teacher to create a supportive educational environment; developing gifted children's ability to apply their knowledge; the research organization, the gifted experimental activities.

At the same time, the study gives grounds to state that in every pedagogical team there are teachers who are ready to work with gifted children, but a minority $(15 \%)$, the majority of educators $(75 \%)$ focused on working with «middle-aged children». Thus, the results obtained during the study allow us to make the conclusion that nursery teachers are not sufficiently prepared to work with the gifted children, and make some recommendations for working with them.

Significance surveys of the different forms of training teachers to work with creative personalities were also conducted during the study. The overwhelming majority of respondents stated that the training for pedagogical employees is not given enough attention to work with gifted children.

As we can see, objectively assessing the multifaceted activities of a nursery teacher with extraordinary personalities is a complex process. Of course, the main criterion for evaluating its activity is the result. Such a result is «... the comprehensive development of an individual as a person and the 
highest value of society, the development of his/her talents, mental and physical abilities, the cultivation of high moral qualities; citizens formation capable for conscious social choice, enrichment of the intellectual, creative, cultural potential of the people on this basis, provision of the national economy with qualified specialists» (Vasylchenko, 2017). But a more objective assessment can be obtained by systematically diagnosing the teaching staff readiness, comparing and analyzing the obtained results, taking into account the impact of one or the other methodical work on the state of their readiness, supplementing its results questionnaires, tests, observations, analysis of personal achievements.

Therefore, in fulfilling this research, we have again convinced ourselves that in our country, there is no due attention to the preparation of the teachers for work with gifted children. Therefore, when planning work with gifted children in preschool education, we recommend that you follow such the orientation measures list that will increase the level of pre-school psychological readiness to work with gifted children:

1. Creating an information database of gifted children from different fields of activity.

2. Conducting problem-thematic seminars in order to systematically improve the educators' skills while working with gifted children.

3. Organization of a permanent consultancy for educators with the involvement of scientists, doctors, psychologists, methodologists.

4. Systematization of periodicals on the children's talent problem.

5. Maintaining the authoring programs and methodological developments aimed at identifying and developing gifted children of preschool age. children.

6. Creating the bank of pedagogical experience in dealing with gifted

7. Formation of groups for individually compatible teaching of gifted children on the basis of one parallel taking into account the level of abilities and sphere of giftedness, each child requests.

8. Involvement of teachers with pedagogical titles as «Methodisteducator» to interact with gifted children.

9. Preparation for printing the materials by work experience, recommendations of pre-school teachers working with gifted children.

10. Monitoring the health of gifted children.

11. Develop a system of moral material encouragement for gifted children and nursery teachers who work with them.

12. Organizing and conducting creative reports of educators on the results of work with gifted children in individual classes, workshops, studios. 
13. Consideration the work organization issues with gifted children and determination of further directions of work at meetings of the educators' methodical associations, pedagogical councils, and meetings with the director.

Based on the above, in our opinion, the pre-school teacher should be helped to develop professional qualities and to increase professional readiness to work with gifted children in three ways:

- by means of trainings i.e. in understanding of oneself and others;

- with the help of psychoeducation i.e. to provide knowledge about learning processes, development, features of different types of giftedness;

- training the skills needed to teach effectively and create the curriculum.

\section{Conclusions}

Thus, the problem of giftedness is now becoming more urgent, and therefore every educator working in pre-school institutions should be improved, look for more and more new ways to work with gifted children, try to create comfortable conditions for such children, to improve and develop themselves, only in that case they will be well psychologically prepared to work with gifted children.

It is also necessary to say that it should be solved the problem of psychological training of nursery teachers precisely for work with gifted children. After all, the educator creates an atmosphere that can inspire children or destroy their self-confidence, or encourage or repress interests.

\section{References}

Afanasyeva, V. (2005). The psychological readiness formation of teachers to work with gifted children. Gifted child, Vol.10, 28-29.

Ananyev, V. (2008). Personality, subject of activity, individuality. Moscow: Direct Media.

Bogoyavlenskaya, D. (2003). Psychology of creative abilities. Samara: Fedorov.

Chudnovskyi, V. (1990). Giftedness: a gift or a test. Moscow: Knowledge.

Gnatko, M., Prymachuk, O. (2008). Psychological preconditions of work with gifted children. Pedagogical search, Vol.4, 15-18.

Demchenko, V. (2008). Preparation of Pedagogical staff for the work with gifted children and its connection with the effectiveness of education and development. New pedagogical thought, 2, 15-19.

Dolynska, L. (2016) Self-realization of personality as a socio-psychological phenomenon. Scientific journal of NPU named after Drahomanov. Series 12: Psychological Sciences, 18-25. 
Duray-Novakova, K. (1983) Formation of professional readiness of students for pedagogical activity: abstract of the dissertation. Moskow.

Dyachenko, M.I., Kandybovych, L.A. (1976). Psychological readiness for activity. Minsk: BGU.

Korol, A. (2010) Traditional and non-traditional teaching methods in the gifted child development. Native school, December, 29-30.

Komisarova, S., Vedmedenko D., Bilogorna, M. (2014). Work with gifted children. Q: B. B. K., 6 .

Kostyuk, O. (2001). Problems of creative psychologists and the development of an approach to the study of giftedness. Children's world, 11, 50-51.

Lipova, L. (2003), Diagnosis of children's talent and psychological and pedagogical features of gifted children. Native school, 5, 9-11.

Molyako, V. (2005) The creative potential of man as a psychological problem. Gifted child, 6, 2-9.

Montessori, M., Gutek, G.L. (2004). The Montessori Method: The Origins of an Educational Innovation: Including an Abridged and Annotated Edition of Maria Montessori's The Montessori Method. Lanham: Rowman \& Littlefield Publishers

Platonov, K. (1972). Problems of abilities. Moscow: Science.

Rubinstein, S. (2000). Abilities. Psychology of individual differences; under ed. Yu. Gippenteiter and V. Romanov. (pp. 20-40). Moscow.

Shchors, V. (2007). How not to make a mistake in identifying early childhood giftedness. Gifted child, 3, 53-62.

Sternberg, R. (2000). Wisdom as a form of giftedness. Gifted Child Quarterly, 44 (4). 252-260.

Tarasova, G. (2005). Organizational and pedagogical conditions for the development of readiness teachers to work with gifted children: dissertation of the candidate of sciences. Kazan.

Teplov, B. (1985). Abilities and talents. Select Works: in 2 volumes. Pedagogy, 1, $15-$ 42.

Torrans, P. (1963). Education and the Creative Potential. University of Minnesota Press.

Vasylchenko, L. (2017). Psychological and pedagogical features of gifted children. Problems of education, No. 4 (57), 32-39.

Zabrodska, S. (2011). Is Giftedness a Feature of only gifted? Gifted child, 1, 19-23. 